BMJ Open

Sport \&

Exercise

Medicine

\section{Leisure time physical activity and quality of life in medical students: results from a multicentre study}

To cite: Peleias M, Tempski P, Paro HBMS, et al. Leisure time physical activity and quality of life in medical students: results from a multicentre study. BMJ Open Sport Exerc Med 2017;3:e000213.

doi:10.1136/bmjsem-2016000213

\section{- Additional material is} published online only. To view, please visit the journal online (http://dx.doi.org/ 10.1136/bmjsem-2016000213).

Accepted 9 April 2017

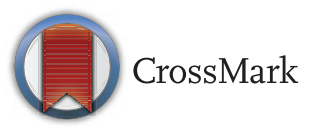

For numbered affiliations see end of article.

Correspondence to Dr Milton A Martins; mmartins@usp.br

\section{ABSTRACT}

Background/aim We evaluated the association between leisure time physical activity (PA) and quality of life (QoL) in medical students. Our hypothesis was that there was a positive association between volume of PA and various domains of perception of QoL. Methods Data were evaluated from a random sample of 1350 medical students from 22 Brazilian medical schools. Information from participants included the WHO Quality of Life questionnaire-short form (WHOQOL-BREF), a questionnaire specifically designed to evaluate QoL in medical students (VERAS-Q) and questions for both global QoL self-assessment and leisure time PA. According to the amount of metabolic equivalents (METs) spend during PA, volunteers were divided into four groups, according to the volume of PA: (a) no PA; (b) low PA, $\leq 540$ MET min/week; (c) moderate PA, from 541 to $1260 \mathrm{MET} \mathrm{min} /$ week and (d) high PA, > $1261 \mathrm{MET}$ min/week.

Results Forty per cent of the medical students reported no leisure time PA (46.0\% of females and $32.3 \%$ of males). In contrast, $27.2 \%$ were classified in the group of high PA $(21.0 \%$ of females and $34.2 \%$ of males). We found significant associations between moderate and high levels of PA and better QoL for all measurements. For low levels of PA, this association was also significant for most QoL measurements, with the exceptions of WHOQOL physical health $(p=0.08)$ and social relationships $(p=0.26)$ domains.

Conclusion We observed a strong dose-effect relationship between the volume of leisure time PA and QoL in both male and female medical students.

\section{INTRODUCTION}

It was previously shown that the levels of psychological distress in medical students are higher than in their age-matched peers. $^{1}{ }^{2}$ In fact, a high prevalence of anxiety and depression among medical students has been reported by many authors. $^{3}{ }^{4}$ There are many reasons for these findings, such as the need to deal with suffering and death, lack of time, competitiveness and an excess of required and/or personal activities, which can decrease

\section{What are the new findings?}

We evaluated a random sample of 1350 medical students from 22 medical schools and compared the volume of leisure time physical activity and quality of life. Forty per cent of the medical students reported no leisure time physical activity $(46.0 \%$ of females and $32.3 \%$ of males). In contrast, $27.2 \%$ were classified in the group of high volume of physical activity $(21.0 \%$ of females and $34.2 \%$ of males). Using the group that reported no leisure time physical activity as the reference group, we observed a strong dose-effect relationship between the volume of leisure time physical activity and quality of life in both male and female medical students.

How might if impact on clinical practice in the near future?

Medical schools must design programmes to incentivate medical students and physicians in training to be more physically active.

quality of life (QoL) and the perception of educational environment. ${ }^{5-10}$ However, there is only limited evidence concerning interventions to improve well-being in medical students, such as the incentive to physical activity (PA) and very few studies that aimed to explore the relationship between PA and QoL in medical students. ${ }^{11-13}$

There are many studies demonstrating that PA behaviour positively influences the personal perception of QoL and wellbeing. ${ }^{14-18}$ PA enhances QoL and the perception of QoL is also a motivator of PA. ${ }^{16}$ QoL is a multidimensional construct, including psychological, physical, social and environmental domains. PA is associated with a better perception of the 
physical aspect of QoL and other domains too, such as social and emotional or psychological aspects of QoL.

In order to increase the proportion of adults who practice PA regularly, it is very important that medical students, residents and physicians in general provide adequate counselling to their patients. It has been shown in medical students that personal PA levels are correlated with the frequency of PA counselling of their patients. ${ }^{20-24}$ In addition, it has been shown that physicians and medical students with a normal body mass index (BMI) and who practice moderate and/or vigorous $\mathrm{PA}$ are more likely to feel confident about counselling their patients about PA than their colleagues who do not practice PA or are overweight. ${ }^{25}$ It is important that counselling about the practice of PA also includes its impact on QoL. However, there are few data concerning the relationship between QoL and PA in medical students and physicians.

In this study, we evaluated the association between levels of leisure time PA and QoL, analysing data from a multicentre random sample of Brazilian medical students. Our hypothesis was that there is a positive association between the volume of physical exercise and various domains of the perception of QoL in medical students.

\section{METHODS}

\section{Study design and sample}

We conducted this investigation, designed to evaluate QoL and leisure-time PA in medical students, as part of a multicentre study involving 22 Brazilian medical schools (the VERAS study, translated to English as 'Students' and Residents' life of health professions'). Medical schools participating in VERAS were geographically distributed across the country, with a diverse legal status and location (13 public and 9 private schools; 13 in state capital cities and 9 in other cities). Data collection was performed from August 2011 to August 2012. The research protocol was approved by the Ethics Committee of the School of Medicine of the University of Sao Paulo and all medical schools included in the study. More details of the VERAS study has been previously published. ${ }^{5} 7826$

When we collected the data for this study, Brazil had 153 medical schools with at least one graduating class, constituting approximately 86000 medical students. We defined our sample size $(n=1152)$ to enable an effect size of 0.165 of the quality of live score between two groups of the same size, with $80 \%$ power at a 0.05 significance level. Later, we increased the sample to 1650 students to account for $30 \%$ loss of participants. We randomly selected at least 60 students from each of 22 medical schools (the participating medical schools provided the list of students). Next, we stratified them into clusters by gender and programme year (ie, five males and five females per each of the six programme years), using a computer-generated list of random numbers. We invited the selected students to participate in the study, contacting them through email and social media. If a student did not respond or accept to participate, we randomly selected another student from the same cluster. Participation was voluntary, and we did not offer any compensation or incentive. We guaranteed both confidentiality and anonymity, and participating students filled a consent form in the electronic platform. ${ }^{57826}$

\section{Data collection}

Selected students received a link to access an electronic survey platform, which we designed specifically for the study. Students had 10 days to complete the survey that consisted of 13 different questionnaires. After submitted the fulfilled questionnaires, students received a feedback on their scores. Specifically, they received the score for each domain of each questionnaire and information about the meaning of each result. We also provided students with the opportunity to contact any of the coordinating researches for guidance or emotional support. ${ }^{5} 7826$

\section{Instruments}

For the present study, we evaluated data from the WHO QoL questionnaire-short form (WHOQOLBREF), the VERAS-Q questionnaire and questions for a global QoL self-assessment and about leisure time PA (see below).

WHOQOL-BREF consists of 26 items clustered in four domains: environment, psychological, social relationships and physical health. Answers are given on a 5-point Likert scale and points within each domain are linearly transformed to a score from 0 to 100 , and higher scores represent better QoL. ${ }^{27}$ This questionnaire was translated and validated to Brazilian Portuguese. $^{28}$

The QoL self-assessment consisted of two questions related to students' perception of their overall QoL and medical school-related quality of life (MSQoL) and the score of each question ranged from 0 to 10 . The items were (1) rate your overall QoL; (2) rate your QoL in medical school.

VERAS-Q is a questionnaire created to evaluate the QoL from students in the health professions (see online supplementary file). ${ }^{29}$ It has 45 statements on a 5-point Likert scale divided in four domains (time management, psychological, physical health and learning environment) and a global score. There is no cut-off, as the score increases the better QoL.

The leisure time PA evaluation consisted of two questions with the purpose to identify if the students had some leisure time PA regularly. The questions were: (a) Which PA, physical exercise and/or sports do you practice regularly? (b) How many hours per week do you practice this PA, physical exercise and/or sports?

The results of the reliability analyses performed using the Cronbach's $\alpha$ coefficient demonstrated that the data ranged from moderate to highly reliable, with 
$\alpha$ value ranging between 0.66 and 0.94 for all domains of the questionnaires (data not shown).

\section{Study variables}

In order to classify the volunteers according to their level of leisure time physical activities, we used the 2011 Compendium of Physical Activities. ${ }^{30}$ The number of metabolic equivalents (METs) of each different physical exercise was multiplied by the number of minutes of practice per week and we obtained, for each volunteer, the total number of METs spent in leisure time PA in a typical week.

Volunteers were classified into four groups, according to the total number of METs spent per week: (a) no PA; (b) low volume of PA, $\leq 540$ MET $\mathrm{min} / \mathrm{week}$; (c) moderate volume of PA, from 541 to $1260 \mathrm{MET} \mathrm{min/}$ week and (d) high volume of PA, >1261 MET min/ week.

\section{Statistical analysis}

Continuous variables were expressed as means and SD and categorical variables as proportions. Chi-squared and analysis of variance tests were used whenever applicable. A linear regression model was built to analyse the association between the volume of leisure time PA and the measurements of QoL in the VERAS study (overall QoL, MSQoL and VERAS-Q and WHOQOL-BREF questionnaires). Models were presented (1) crude; (2) adjusted for age, sex and year of medical course. An interaction model was built to study if the association between the level of PA and the measurements of QoL was heterogeneous according to gender. These interaction models pointed to different strengths of associations between males and females. Therefore, a crude and an adjusted by gender post hoc stratified model were also presented. Analyses were performed using R software V.3.2.0. Significance level was set at 0.05 .

\section{RESULTS}

Of 1650 randomly selected students, 1350 (81.8\%) accepted to participate and completed the study. The main reason to refuse to participate in the study (16.6\%) was lack of time. In our sample, 714 individuals (52.9\%) were females, $459(34.0 \%)$ were in the first and second years of medical course (basic sciences), $491(36.4 \%)$ were in the third and fourth years (clinical sciences) and $400(29.6 \%)$ were in the last 2 years (clerkships). Their ages ranged between 17 and 40 years $(22.8 \pm 1.3$, mean \pm SD).

Mean BMI of the medical students was $21.8 \pm 3.3 \mathrm{~kg} /$ $\mathrm{m}^{2}$ for females and $24.6 \pm 3.5 \mathrm{~kg} / \mathrm{m}^{2}$ for males $(p<0.001)$. There were no significant difference in BMI among the four groups of medical students $\left(22.8 \pm 3.8, \quad 23.3 \pm 3.4, \quad 23.4 \pm 3.8\right.$ and $\quad 23.3 \pm 3.4 \mathrm{~kg} / \mathrm{m}^{2}$, respectively, for students with no $\mathrm{PA}$, low, moderate and high volume of leisure time PA).
Table 1 shows the results of QoL, MSQoL, VERAS-Q and WHOQOL-BREF. Mean values for the whole sample as well as values for males and females are shown. Males had higher WHOQOL physical health $(\mathrm{p}<0.001)$ and psychological $(\mathrm{p}<0.001)$ domain scores. In addition, they also had higher VERAS- $Q$ time management $(\mathrm{p}<0.001)$, psychological $(\mathrm{p}<0.001)$, physical health $(\mathrm{p}<0.001)$ domain scores and global scores $(\mathrm{p}<0.001)$. Overall and MSQoL self-assessment had no significant differences according to gender.

Table 1 also shows the number (and percentages) of medical students (total, males and females) that reported no leisure time $\mathrm{PA}$, or were classified in the groups of low, moderate or high PA. Forty per cent of medical students reported no leisure time PA (46.0\% of female and $32.3 \%$ of male medical students). In contrast, $27.2 \%$ were classified in the group of high volume leisure time PA (21.0\% of females and $34.2 \%$ of males).

Beta-coefficients for the association between QoL measurements and level of leisure time PA in raw data and data adjusted for sex, age and year of medical course are shown in tables 2 and 3 . Using the group that reported no leisure time PA as the reference group, there was a significant association between moderate and high levels of leisure time PA and better QoL for all measurements. For low volume of PA, this association was also significant for most QoL measurements, with the exceptions of WHOQOL physical health $(p=0.08)$ and social relationships $(p=0.26)$ domains, in which only a non-significant trend towards a positive association was observed.

An interaction model was built to analyse if the association between QoL measurements and level of leisure time PA was homogeneous in males and female. In tables 4 and 5 , the results of the interaction models are presented, using raw data and data adjusted for sex, age and year of medical course. We observed a significant interaction for high volume of leisure time PA and general QoL $(p=0.04)$, WHOQOL environment $(\mathrm{p}<0.001)$ domain (table 4) and VERAS-Q physical health $(\mathrm{p}<0.001)$ and educational environment $(\mathrm{p}=0.04)$ domains (table 5).

\section{DISCUSSION}

The main finding of our study was a strong positive dose-effect relationship between the volume of leisure time PA and QoL, in both male and female medical students. To our knowledge, there was no previous work specifically designed to evaluate the relationship between leisure time PA and various dimensions of QoL in a large random sample of medical students.

There are many previous studies, including some systematic reviews and meta-analyses that demonstrated that PA enhances QoL. ${ }^{14-17}$ In many of these studies, both physical exercise professionals and participants of the programmes recognise that a better QoL is a benefit and a motivator of PA. However, QoL is a multidimensional construct that is not easily defined, 


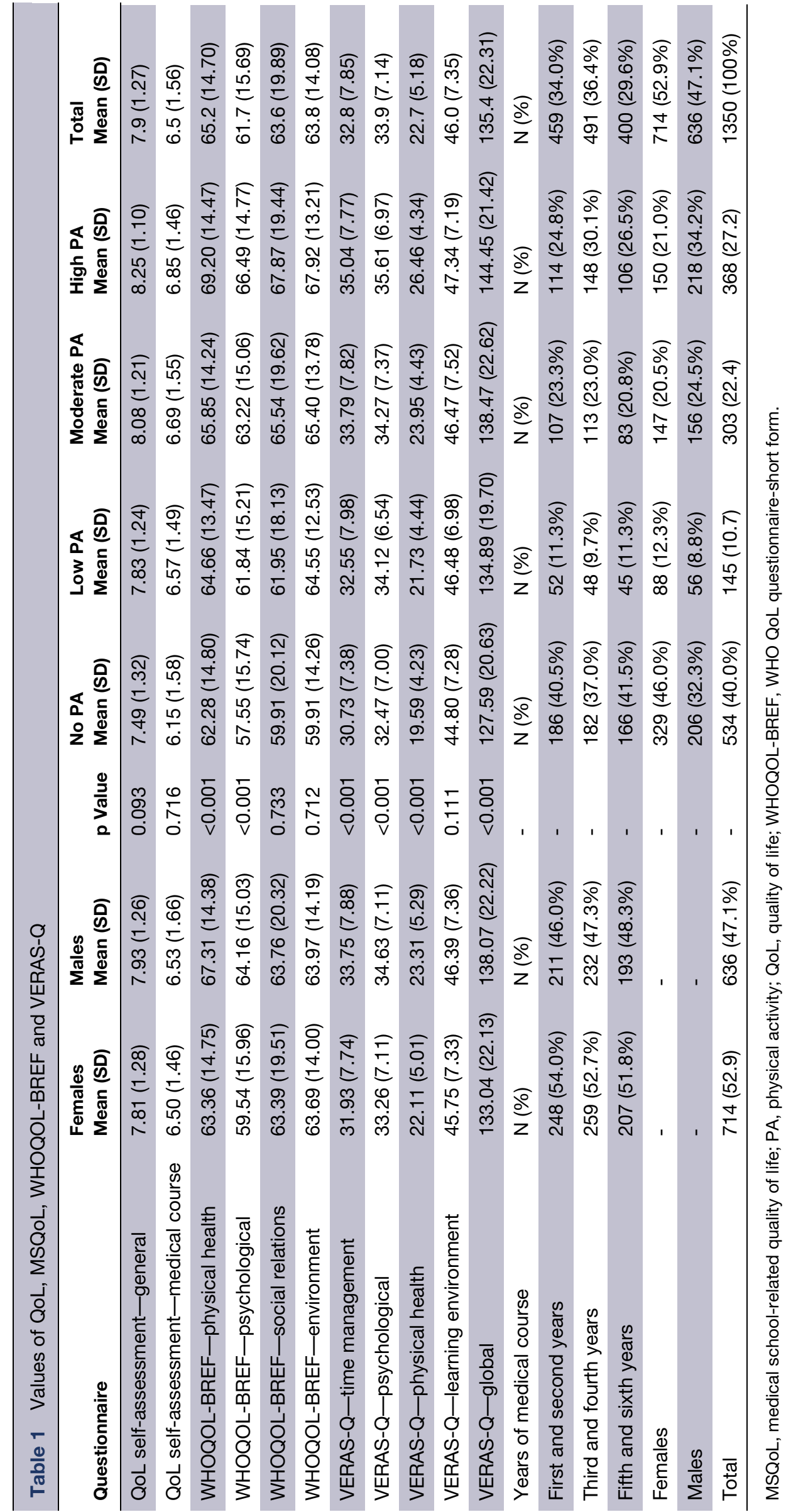

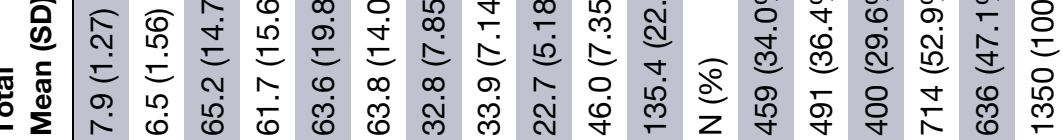

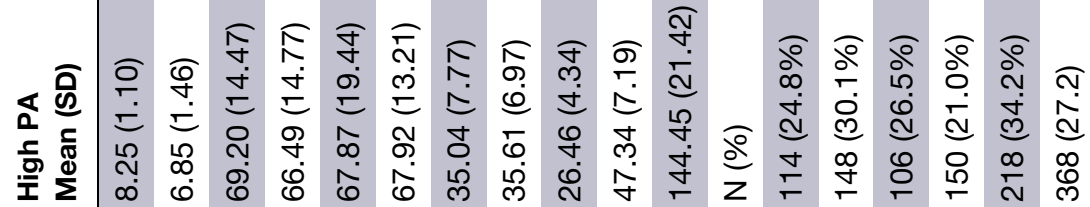

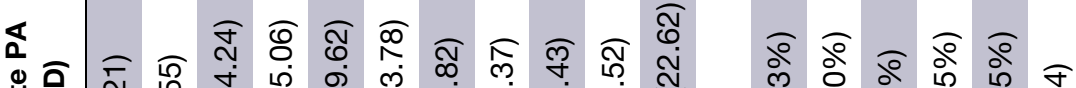

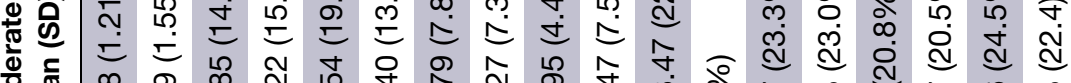

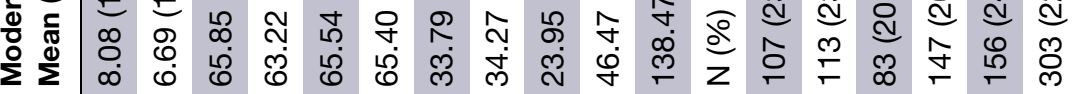

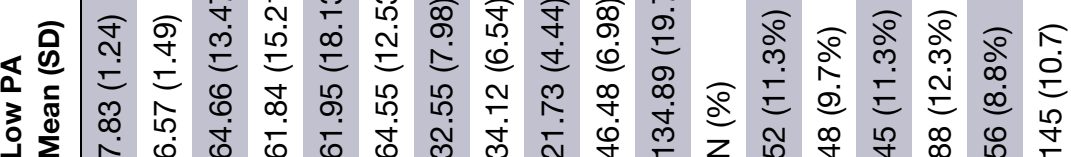

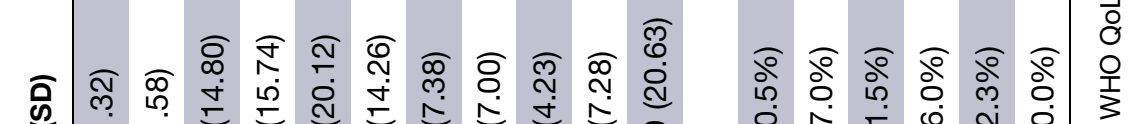

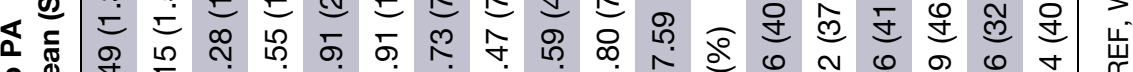
z $\Sigma$ 守

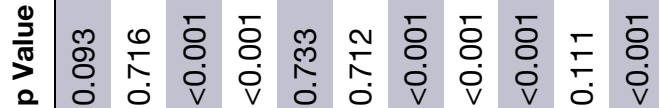

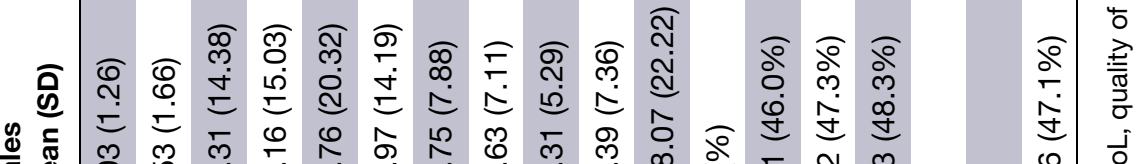

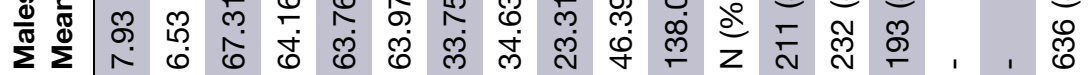

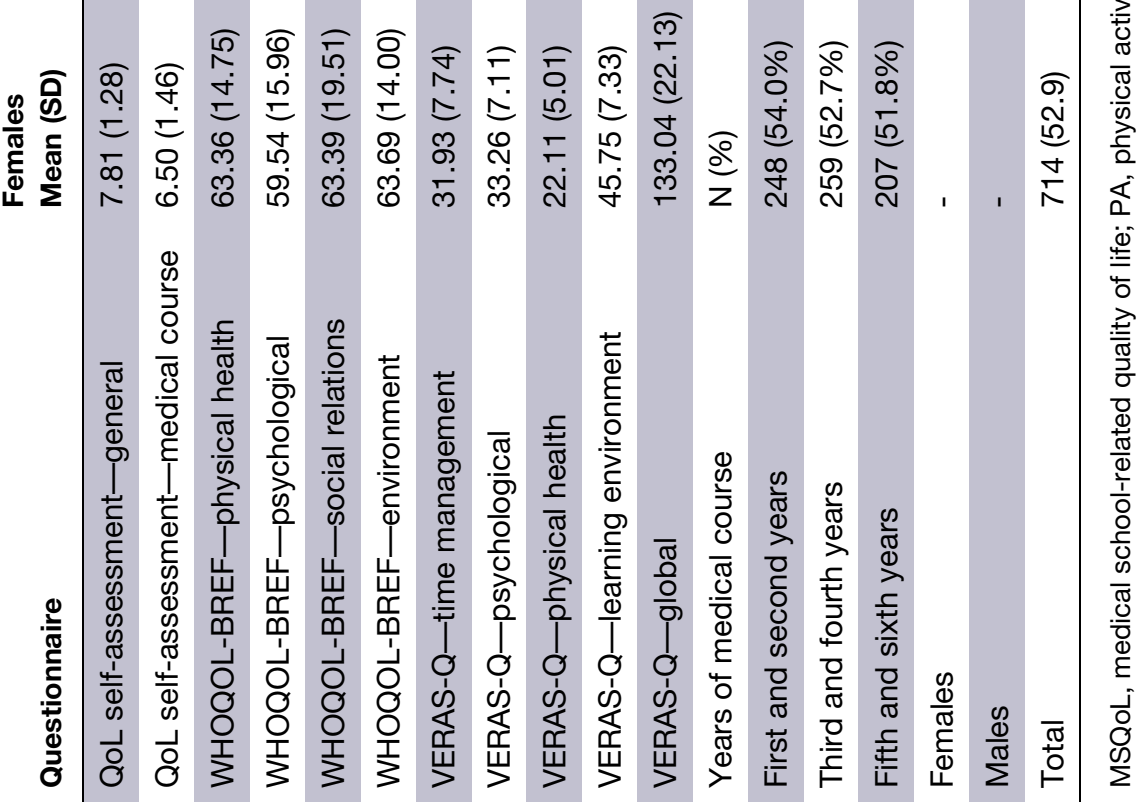


Table 2 Beta-coefficients of the association between leisure time PA and QoL self-assessment and WHOQOL-BREF domains

\begin{tabular}{|c|c|c|c|}
\hline Questionnaire & PA volume & $\begin{array}{l}\text { Raw data } \\
\text { Beta (Cl) }\end{array}$ & $\begin{array}{l}\text { Adjusted data } \\
\text { Beta (CI) }\end{array}$ \\
\hline \multirow[t]{3}{*}{ QoL self-assessment-general } & No & Ref. & Ref. \\
\hline & Moderate & 0.59 (0.42 to 0.77$)$ & $0.58(0.41$ to 0.76$)$ \\
\hline & High & 0.76 (0.60 to 0.92$)$ & 0.74 (0.57 to 0.91$)$ \\
\hline \multirow{3}{*}{ QoL self-assessment-medical course } & Low & $0.42(0.14$ to 0.7$)$ & $0.42(0.14$ to 0.70$)$ \\
\hline & Moderate & 0.54 (0.32 to 0.76$)$ & $0.54(0.32$ to 0.76$)$ \\
\hline & High & 0.70 (0.50 to 0.90$)$ & 0.71 (0.50 to 0.92$)$ \\
\hline \multirow[t]{2}{*}{ WHOQOL-BREF-physical health } & No & Ref. & Ref. \\
\hline & High & 6.92 (5.0 to 8.84$)$ & 6.25 (4.31 to 8.18$)$ \\
\hline \multirow[t]{4}{*}{ WHOQOL-BREF-environment } & No & Ref. & Ref. \\
\hline & Low & $4.63(2.12$ to 7.15$)$ & 4.69 (2.19 to 7.19$)$ \\
\hline & Moderate & 5.48 (3.55 to 7.42$)$ & 5.52 (3.59 to 7.45$)$ \\
\hline & High & 8.00 (6.19 to 9.82$)$ & 7.93 (6.09 to 9.77$)$ \\
\hline \multirow[t]{3}{*}{ WHOQOL-BREF-psychological } & No & Ref. & Ref. \\
\hline & Low & 4.29 (1.48 to 7.09$)$ & 4.25 (1.47 to 7.04$)$ \\
\hline & Moderate & 5.66 (3.51 to 7.82 ) & 5.16 (3.01 to 7.31$)$ \\
\hline
\end{tabular}

Adjusted data-data adjusted for sex, age and year of medical course.

PA, physical activity; QoL, quality of life; WHOQOL-BREF, WHO QoL questionnaire-short form.

but in most conceptual models include physical, social, mental and environmental well-being. ${ }^{16} 27$ To better address the relationship between PA and QoL, we used two global scores (QoL in general and QoL in medical course) and two different questionnaires: the first (WHOQOL-BREF) has been widely used and has four domains (environment, psychological, social relationships and physical health). ${ }^{27}$ In addition, we used a questionnaire specifically designed to evaluate QoL in medical students. In previous studies, factor analysis of this questionnaire resulted in four domains: time management, psychological, physical health and learning environment. ${ }^{29}$ Interestingly, in a recent study focusing the relationship between PA and QoL, Gill et al observed that university students valued more the social, physical health and emotional dimensions of QoL. ${ }^{16}$
In a recent systematic review, Rotenstein et al observed an estimate of the prevalence of depression or depressive symptoms in $27.2 \%$ of medical students and $11.1 \%$ of suicidal ideation. ${ }^{3}$ Strategies do deal with this important problem have been discussed, and since it is well known that regular PA has beneficial effects to people with depressive and/or anxiety symptoms, ${ }^{19} 31$ 32 it is important to know the relationship between PA and well-being in medical students. Regular PA may be protective against the development of depression, while physical inactivity may increase the risk of the development of depression. Previous studies reported a positive effect of regular PA on mood, as well as in self-esteem, general well-being, vitality and satisfaction with physical appearance. ${ }^{19} 3132$ Although the positive effect of regular PA on depressive and/or anxiety symptoms have mainly been studied using aerobic exercise, 
Table 3 Beta-coefficients of the association between leisure time PA and VERAS-Q domains

\begin{tabular}{|c|c|c|c|}
\hline Questionnaire & PA volume & $\begin{array}{l}\text { Raw data } \\
\text { Beta (CI) }\end{array}$ & $\begin{array}{l}\text { Adjusted data } \\
\text { Beta (CI) }\end{array}$ \\
\hline \multirow[t]{3}{*}{ VERAS-Q_time management } & No & Ref. & Ref. \\
\hline & Moderate & 3.06 (1.98 to 4.14$)$ & 2.86 (1.78 to 3.94$)$ \\
\hline & High & 4.31 (3.29 to 5.33$)$ & 4.05 (3.02 to 5.08$)$ \\
\hline \multirow{3}{*}{ VERAS-Q_psychological } & Low & 1.65 (0.36 to 2.94$)$ & 1.63 (0.34 to 2.92$)$ \\
\hline & Moderate & $1.8(0.81$ to 2.79$)$ & 1.67 (0.67 to 2.66$)$ \\
\hline & High & $3.14(2.21$ to 4.07$)$ & 2.99 (2.04 to 3.94$)$ \\
\hline \multirow[t]{2}{*}{ VERAS-Q—physical health } & No & Ref. & Ref. \\
\hline & High & 6.87 (6.3 to 7.45$)$ & 6.79 (6.21 to 7.38$)$ \\
\hline \multirow[t]{4}{*}{ VERAS-Q_learning environment } & No & Ref. & Ref. \\
\hline & Low & 1.68 (0.35 to 3.02$)$ & 1.67 (0.36 to 2.98$)$ \\
\hline & Moderate & 1.67 (0.64 to 2.69$)$ & $1.53(0.52$ to 2.55$)$ \\
\hline & High & 2.54 (1.58 to 3.51$)$ & 2.46 (1.5 to 3.42$)$ \\
\hline \multirow[t]{3}{*}{ VERAS-Q-global } & No & Ref. & Ref. \\
\hline & Low & 7.3 (3.4 to 11.19$)$ & 7.25 (3.38 to 11.12$)$ \\
\hline & Moderate & 10.88 (7.89 to 13.87$)$ & 10.38 (7.39 to 13.36$)$ \\
\hline
\end{tabular}

Adjusted data—data adjusted for sex, age and year of medical course PA, physical activity.

there are also evidences of a similar effect of resistive or flexibility training. ${ }^{33}$ In our study, all types of PA were included in our analysis, classified only by the amount of METs spent.

Female medical students had lower scores in some domains of the questionnaires of QoL (table 1). The differences between males and females students were statistically significant in two domains of WHOQOLBREF (physical health and psychological) and in the global score of VERAS-Q and time management, psychological and physical health domains of this questionnaire. These observations are consistent with previous studies that suggested that female students face greater difficulties in medical school and have higher rates of depression, worse well-being and higher levels of academic stress. ${ }^{34}$ In our study, we observed a dose-response effect of the volume of leisure time PA in all domains of the studied questionnaires for both male and female medical students. However, we observed that in QoL self-assessment in medical course, in WHOQOL-BREF environment domain and in VERAS-Q physical health and learning environment domains there were significantly higher values of the beta-coefficients for males in the high volume of PA group. There are previous works showing that intense physical activities can be associated with worsening of mood or well-being. ${ }^{17} 19$ Maybe the intensity of PA reached a level that was not beneficial to some female students, suggesting that female medical students that are engaged in vigorous training must receive a closer supervision.

In our study, $40.0 \%$ of medical students reported no leisure time PA. This percentage is very similar to previous studies performed in the USA and Canada, which showed that the percentage of medical students that met the respective national PA recommendations were, respectively, $61 \%$ (USA) and 64\% (Canada). ${ }^{25} 35$ In our study, this percentage was not significantly different when we compared students from the first and the last years of medical school, suggesting that there was no effective incentive to increasing PA during medical course.

Although there is a large amount of evidence about the health benefits of PA and also the effectiveness of PA counselling by physicians, only $34 \%$ of the US adults reported that had received exercise counselling in their last medical visit. ${ }^{24}$ Previous studies showed a positive relationship between the personal PA behaviour of 


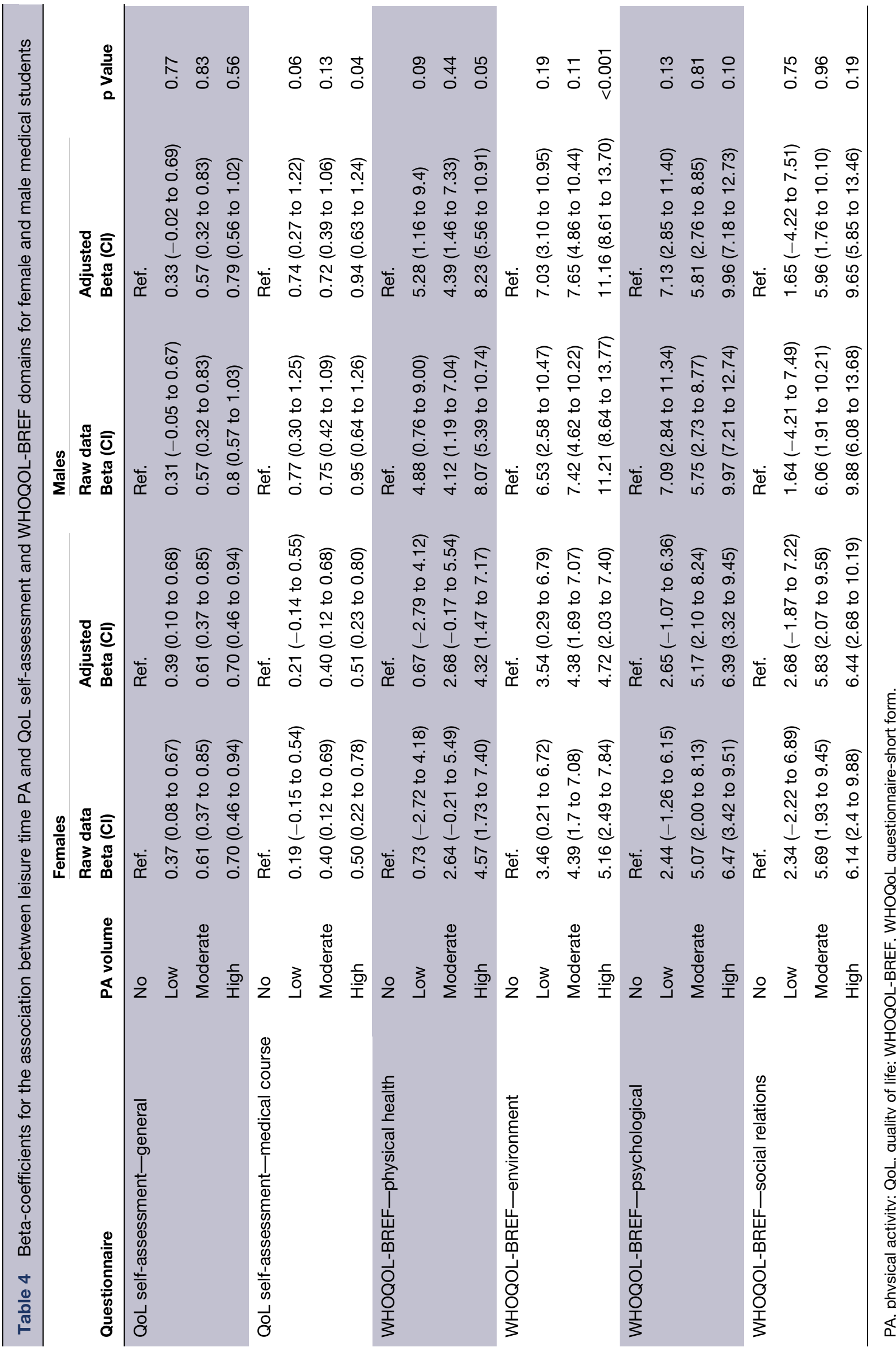




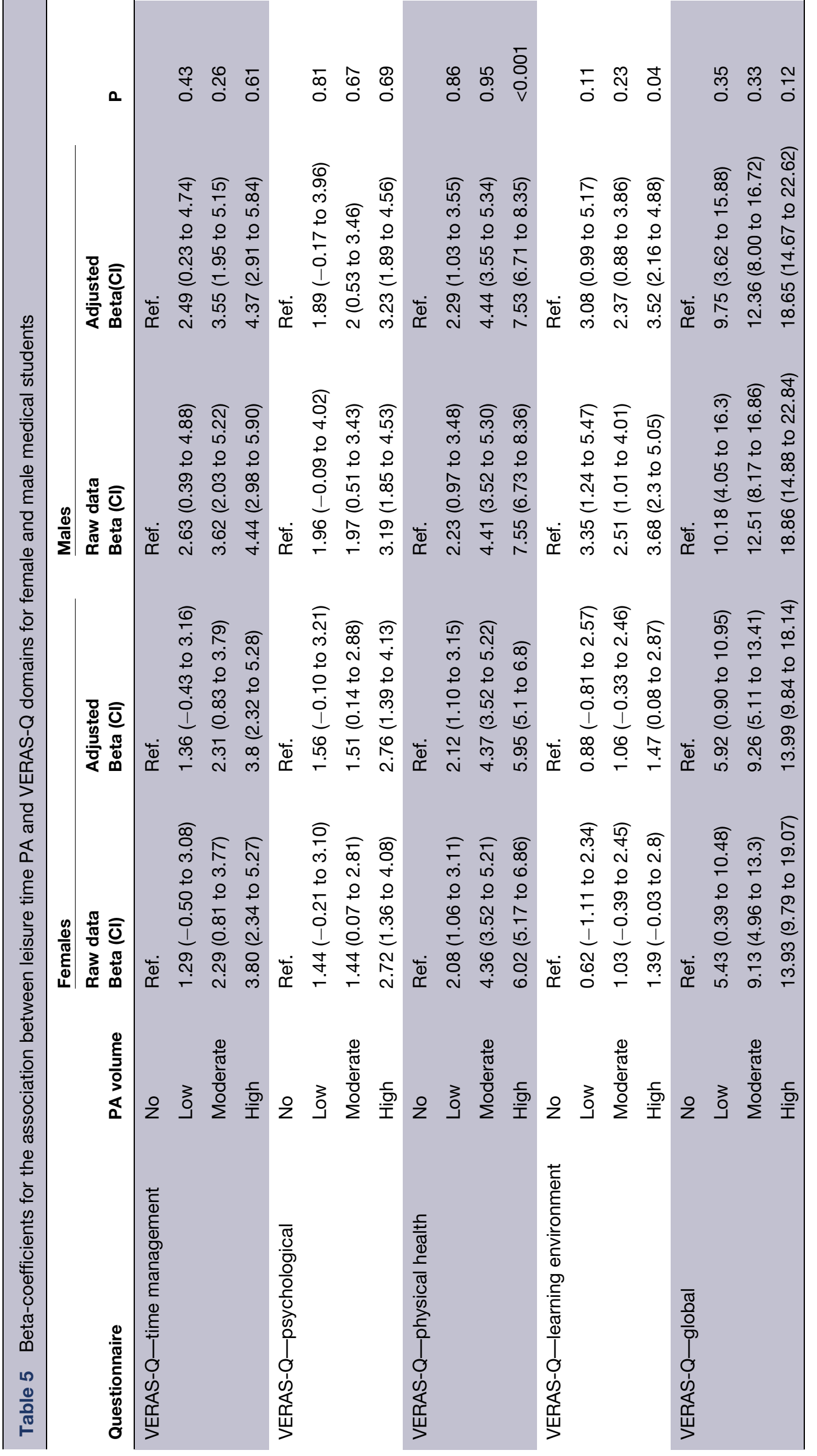

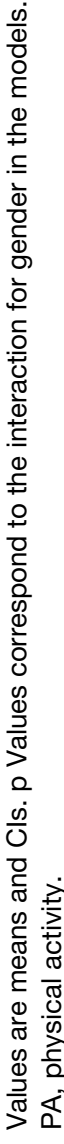


physicians and their practice of giving advice concerning PA to their patients. ${ }^{24}{ }^{25}$ Frank et al observed the same relationship between PA levels and counselling practices of the US medical students. ${ }^{22}$ In addition, Stanford et al showed that physicians and medical students with a normal BMI and who met the guidelines to moderate or vigorous PA were more likely to feel confident about counselling patients about PA than who did not meet the guidelines or were overweight or obese. $^{25}$

It is very important for medical schools to develop strategies to incentive medical students to have healthier habits, including the practice of regular PA, and also to have programmes to better train medical students to counsel patients about PA. ${ }^{11} 1235$ The benefits of this approach will be both a better QoL of medical students, and a better present and future practice of counselling their patients about PA. There are some reports of programmes specifically designed to increase PA among medical students and residents. Ball and Bax reported the results of an intervention to improve health habits for first-year medical students that influenced positively sleep and activity behaviour. ${ }^{11}$ Weight $e t$ al reported that a programme to incentive PA designed for medical residents and fellows resulted in an increase in the percentage of people that met the recommendations for activity, a better QoL and lower burnout scores. ${ }^{36}$

Our study has important strengths. Our sample was randomly selected to reduce response bias, often present in convenience samples. In addition, we were able to obtain a high response rate $(81.8 \%)$. Our study included 1350 medical students from 22 medical schools representing diverse curricula and all regions of Brazil, a very large country.

The main limitation of our study was its cross-sectional design that does not allow definitive conclusions about causal relationships. Other limitation of our study was that we did not measure the total amount of METs spent in a typical week of the participants, only the METs spent in leisure time PA. However, we studied a very homogeneous population that spend most of their time in classrooms, laboratories, clerkships and other learning activities, and it is possible to assume that the energy expenditure during their daily activities did not vary substantially. In addition, PA levels were provided by self-report, and not directly measured.

In conclusion, we observed a strong dose-effect relationship between the volume of leisure time PA and various dimensions of QoL of medical students. This effect was observed in both male and female medical students.

\footnotetext{
Author affiliations

${ }^{1}$ Center for Development of Medical Education, School of Medicine of the University of Sao Paulo, Sao Paulo, Brazil

${ }^{2}$ Departments of Medicine, School of Medicine of the University of Sao Paulo, Sao Paulo, Brazil

${ }^{3}$ Department of Obstetrics and Gynecology, Federal University of Uberlandia, Uberlandia, Brazil
}

${ }^{4}$ Evangelical Medical School of Parana, Curitiba, Brazil

${ }^{5}$ University of the City of São Paulo, Sao Paulo, Brazil

${ }^{6}$ Federal University of Goias, Goiania, Brazil

${ }^{7}$ Department of Pathology, School of Medicine of the University of Sao Paulo, Sao Paulo, Brazil

${ }^{8}$ Department of Physical Therapy, School of Medicine of the University of Sao Paulo, Sao Paulo, Brazil

Acknowledgements The authors would like to thank the associate researchers, members of the VERAS Collaborative Research Group, for their hard work recruiting students. The authors would also like to thank the participating students for their willingness to complete the questionnaires.

Contributors Conceived and designed the experiments: MP, PT, HBMSP, BP, SCE, SG, MADP, PSS, CFC, MAM. Created the electronic platform for data collection: PSS. Performed the data collection: MP, PT, HBMSP, BP, FBM, SCE, SG, PSS, CFC, MAM. Analysed the data: MP, PT, ISS, MAM. Wrote and revised the manuscript: MP, PT, HBMSP, BP, FBM, SCE, SG, MADP, PSS, ISS,CFC, MAM.

Funding The study was supported by the following Brazilian scientific agencies: Nacional Council for Scientific and Technological Development (CNPq), Coordination for the Improvement of Higher Education Personnel (CAPES) and São Paulo Research Foundation (FAPESP).

Competing interests None declared.

Patient consent Obtained from patients.

Ethics approval The research protocol was approved by the Ethics Committee of the School of Medicine of the University of Sao Paulo and all medical schools included in the study.

Provenance and peer review Not commissioned; externally peer reviewed.

Data sharing statement All additional unpublished data from the study are available on request to Milton A Martins, MD (email: mmartins@usp.br).

Open Access This is an Open Access article distributed in accordance with the Creative Commons Attribution Non Commercial (CC BY-NC 4.0) license, which permits others to distribute, remix, adapt, build upon this work noncommercially, and license their derivative works on different terms, provided the original work is properly cited and the use is non-commercial. See: http:// creativecommons.org/licenses/by-nc/4.0/

(C) Article author(s) (or their employer(s) unless otherwise stated in the text of the article) 2017. All rights reserved. No commercial use is permitted unless otherwise expressly granted.

\section{REFERENCES}

1. Dahlin M, Joneborg N, Runeson B. Stress and depression among medical students: a cross-sectional study. Med Educ 2005;39:594-604.

2. Dyrbye LN, Thomas MR, Shanafelt TD. Systematic review of depression, anxiety, and other indicators of psychological distress among U.S. and canadian medical students. Acad Med 2006;81:354-73.

3. Rotenstein LS, Ramos MA, Torre M, et al. Prevalence of depression, depressive symptoms, and suicidal ideation among medical students: a systematic review and Meta-Analysis. JAMA 2016;316:2214-36.

4. Brenneisen Mayer F, Souza Santos I, Silveira PS, Mayer FB, Santos IS, et al. Factors associated to depression and anxiety in medical students: a multicenter study. BMC Med Educ 2016;16 (1):282.

5. Enns SC, Perotta B, Paro HB, et al. Medical students' Perception of their Educational Environment and Quality of Life: is there a positive association? Acad Med 2016;91:409-17.

6. MacLeod RD, Parkin C, Pullon S, et al. Early clinical exposure to people who are dying: learning to care at the end of life. Med Educ 2003;37:51-8.

7. Tempski $\mathrm{P}$, Bellodi PL, Paro HB, et al. What do medical students think about their quality of life? A qualitative study. BMC Med Educ 2012;12:106.

8. Tempski P, Santos IS, Mayer FB, et al. Relationship among medical student resilience, Educational Environment and Quality of Life. PLoS One 2015;10:e0131535. 
9. Wear D. "Face-to-face with It": medical students' narratives about their end-of-life education. Acad Med 2002;77:271-7.

10. Wolf TM, Stress WTM. Stress, coping and health: enhancing wellbeing during medical school. Med Educ 1994;28:8-17.

11. Ball S, Bax A. Self-care in medical education: effectiveness of health-habits interventions for first-year medical students. Acad Med 2002; 77:911-7.

12. Tol A, Tavassoli E, Shariferad GR, et al. Health-promoting lifestyle and quality of life among undergraduate students at school of health, Isfahan university of medical sciences. J Educ Health Promot 2013;2:11.

13. Wasson LT, Cusmano A, Meli L, Lell L et al. Association between Learning Environment Interventions and Medical Student Well-being: a systematic review. JAMA 2016;316:2237-52.

14. Bize R, Johnson JA, Plotnikoff RC. Physical activity level and healthrelated quality of life in the general adult population: a systematic review. Prev Med 2007:45:401-15.

15. Brown DW, Brown DR, Heath GW, et al. Associations between physical activity dose and health-related quality of life. Med Sci Sports Exerc 2004;36:890-6.

16. Gill DL, Hammond CC, Reifsteck EJ, et al. Physical activity and quality of life. J Prev Med Public Health 2013;46 Suppl 1:S28-S34.

17. Klavestrand $\mathrm{J}$, Vingård $\mathrm{E}$. The relationship between physical activity and health-related quality of life: a systematic review of current evidence. Scand J Med Sci Sports 2009;19:300-12.

18. Pucci GC, Rech CR, Fermino RC, et al. Association between physical activity and quality of life in adults. Rev Saude Publica 2012;46:166-79.

19. Peluso MA, Guerra de Andrade LH, Andrade L. Physical activity and mental health: the association between exercise and mood. Clinics 2005;60:61-70.

20. Duperly J, Lobelo F, Segura C, et al. The association between Colombian medical students' healthy personal habits and a positive attitude toward preventive counseling: cross-sectional analyses. BMC Public Health 2009;9:218.

21. Frank E, Carrera JS, Elon L, et al. Predictors of US medical students prevention counseling practices. Prev Med 2007;44:76-81.

22. Frank $\mathrm{E}$, Tong $\mathrm{E}$, Lobelo $\mathrm{F}$, et al. Physical activity levels and counseling practices of U.S. medical students. Med Sci Sports Exerc 2008;40:413-21.
23. Holtz KA, Kokotilo KJ, Fitzgerald BE, et al. Exercise behaviour and attitudes among fourth-year medical students at the University of British Columbia. Can Fam Physician 2013;59:e26-32.

24. Lobelo F, Duperly J, Frank E. Physical activity habits of doctors and medical students influence their counselling practices. Br J Sports Med 2009;43:89-92.

25. Stanford FC, Durkin MW, Stallworth JR, et al. Factors that influence physicians' and medical students' confidence in counseling patients about physical activity. J Prim Prev 2014;35:193-201.

26. Paro HB, Silveira PS, Perotta B, et al. Empathy among medical students: is there a relation with quality of life and burnout? PLOS One 2014;9:e94133.

27. WHOQOL GROUP. The World Health Organization Quality of Life assessment (WHOQOL): position paper from the World Health Organization. Soc Sci Med 1995;41:1403-9.

28. Fleck MP, Louzada S, Xavier M, et al. [Application of the portuguese version of the abbreviated instrument of quality life WHOQOL-bref]. Rev Saude Publica 2000;34:178-83.

29. Tempski P, Perotta B, Pose RA, et al. A questionnaire on the quality of life of medical students. Med Educ 2009;43:1107-8.

30. Ainsworth BE, Haskell WL, Herrmann SD, et al. 2011 Compendium of physical activities: a second update of codes and MET values. Med Sci Sports Exerc 2011;43:1575-81.

31. Mammen G, Faulkner G. Physical activity and the prevention of depression: a systematic review of prospective studies. Am J Prev Med 2013;45:649-57.

32. Jacka FN, Berk M. Depression, diet and exercise. Med J Aust 2012;1:21-3.

33. Stanton R, Happell BM. An exercise prescription primer for people with depression. Issues Ment Health Nurs 2013;34:626-30.

34. Backovic DV, Zivojinovic JI, Maksimovic J, et al. Gender differences in academic stress and burnout among medical students in final years of education. Psychiatr Danub 2012;24:175-81.

35. $\mathrm{Ng} \mathrm{V}$, Irwin JD. Prescriptive medicine: the importance of preparing canadian medical students to counsel patients toward physical activity. J Phys Act Health 2013;10:889-99.

36. Weight CJ, Sellon JL, Lessard-Anderson CR, et al. Physical activity, quality of life, and burnout among physician trainees: the effect of a team-based, incentivized exercise program. Mayo Clin Proc 2013;88:1435-42. 